\title{
ASIA Assessment of Spinal Cord Injury-History
}

\author{
RIdvan ALACA \\ Liv Hospital, Department of Physical Medicine and Rehabilitation, Ankara, Turkey
}

\begin{abstract}
Performing a standardized physical examination for the spinal cord injury patients is mandatory for clinical and scientific purposes. Several attempts have been made since 1960 s to have a standard of assessment. This article includes the history, development, and improvement of ASIA classification, the most widely accepted and used assessment in the field.

Keywords: Spinal cord injury, international standards, neurologic level, ASIA impairment scale
\end{abstract}

\section{Introduction}

Since the 1960s, several studies have been conducted by various authorities and institutions to provide an accurate and complete communication between clinicians and researchers working with patients having spinal cord injury $(\mathrm{SCl})$ and to standardize the gaps in neurological classification. The clinical benefits of this classification are as follows:

1.Assessing the intensity of injury

2.Determining the level

3.Planning appropriate rehabilitation

4.Estimating accurate prognosis

5.Monitoring the healing process

6.Evaluating the effects of different treatment methods.

In scientific studies, such standardization provides a basis for research protocols and facilitates a common language among researchers (1).

Many proposals have been suggested to facilitate standardization in the past years (2). First attempts for standardization be- gan with the questionnaire sent by Michaelis (2) to clinicians and researchers dealing with MSY in different countries in 1967; the results obtained were published in 1969 . The published results highlight the need for neurological terminology and prognosis.

In another publication in the journal in the same year, Frankel et al. (3) reported a classification system that was commonly used for $\mathrm{SCl}$ at that time and is even currently in use. The classification, which provided categories, namely, A, B, C, D, and E, was characterized to be "raw" by Frankel et al. (3) and provided the basis for future classifications.

Subsequently, until 1982, many classifications were put forward based on the bone level, injury mechanism, neurological function, and functional outcome.

The American Spinal Injury Association (ASIA) named this classification system as the International Standards for Neurological Classification of Spinal Cord Injury (ISNCSCI) at its Annual Meeting in 1982 and rearranged (4). It has been made more consistent and reliable, benefiting from the classification provided by Frankel et al. The classification categorized $\mathrm{SCl}$ between levels $A$ and $E$, and the motor scoring described by Lucas et al. (5) was used. Twenty-nine dermatomes were assessed, of which $\mathrm{S4}$ 
and S5 were considered as separate dermatomes. Furthermore, preservation below the injury level and complete/incomplete injury were described. With respect to the form of injury, the terms paraparesis and tetraparesis were also used in addition to paraplegia and tetraplegia. Injury zone was defined up to three levels towards distal. The neurological zone of the injury and incomplete anatomical syndromes were also described in this classification system.

Between 1982 and 1990, the Frankel scale was redefined; motor levels and dermatomes were more clearly defined, and key anatomical points used during dermatome examination were described. The S4 and S5 dermatomes were combined and

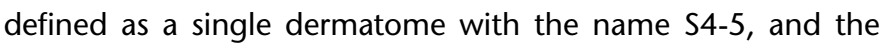
number of dermatomes was reduced to 28 . The definition of "partially protected region" was included in the classification. However, the use of the terms paraparesis and tetraparesis was discontinued (6).

"Sacral protection" was included in the definition in 1991, and the differentiation of complete/incomplete was made clear (7).

The International Spinal Cord of Society (ISCoS), initially known as the International Medical Society of Paraplegia (IMSoP), accepted the ASIA classification at its annual meeting in Barcelona in 1992 and recommended the classification to its members. Since then, the term "ASIA Impairment Scale" (AIS) was used instead of the Frankel scale. Complete and incomplete definitions were more clearly described with the inclusion of sacral protection to the scale. Moreover, the functional independence measure was added to the scale. Sensory points were made clear, light touch and pinprick sensations were described, and the use of "0-1-2" rating was started. Muscle strength of $4 / 5$ during the motor examination was classified as abnormal. Similarly, the definition of partially protected region was modified. Optional tests, such as the examination of deep senses, were included, and it was advised that the term "tetraplegia" be used instead of "quadriplegia" (8).

After printing the reference manual in 1994, some revisions were made to the classification in 1996. The name of the classification was revised to the International Standards for Neurological and Functional Classification of Spinal Cord Injury. Motor scoring was further clarified, and the ABS C-D differentiation was described. It was reported that it was necessary to determine T2-L1 and S2-4 levels, for which motor scoring could not be conducted, with sensory scores (9).

In 2000, the functional independence measure was excluded from the classification, and its name was revised to ISNCSCI. Moreover, motor incomplete was defined (ABS C-D), and three levels of caudal injury for partially protected region were defined (10).

Minor revisions were made to the ASIA classification in 2002, 2006, and 2008; "non key muscles" was mentioned for the first time in 2003 (6). Updates and applications of the International Standards Committee were explained by an article published in 2009 (11).
The "International Standards Training e-Learning Program" (InSTeP) was established in 2010 and was made functional online. This program gave a detailed description of the methods of examining patients with $\mathrm{SCl}$ in accordance with the ASIA classification and with the help of videos (12).

Comprehensive changes were made to the ASIA classification system in 2011. Motor and sensory examinations were re-described in detail and also included in the InSTeP program. The statement that "if motor function is intact in the rostral at the levels of C1-4, T2-L1, and S2-5, which can be determined only as sensorial, sensory level is determined as motor level" was added. The definition of partially preserved region was re-described. It was recommended that the differentiation of ABS B-C should be performed according to the motor level in both sides, and the differentiation of ABS C-D should be performed according to a single neurological level. Furthermore, it was mentioned that muscles, which were not essential ("non key muscles"), should be used in ABS B-C. The use of "deep anal pressure" was recommended instead of "deep anal sensation." If C2 sensation was abnormal, the level was suggested to be $\mathrm{C} 1$. It was emphasized that the partially protected region would be separately specified in the right and left side. The term "neurological level of injury" was suggested for partially innerve dermatomes and myotomes in the caudal of sensation and motor levels. It was reported that motor and sensation levels had to be separately specified. The last level in the healthy caudal in both sides was defined as the "single neurological level." Corrections were made in the examination form (13). These changes were translated into our language and published in 2012 (14).

The last changes were made in 2013. Here the changes in the form were at the forefront. Moreover, the neurological level of the injury was defined and included in the assessment form, and the "non key muscles" were added to the form (6).

The ASIA International Standards Committee reviews ISNCSCI and all the other studies published in that period according to its validity and reliability once every 3 years. The ASIA Education Committee reviews InSTeP in coordination with ISNCSCI once every 3 years.

There will always be cases that fail to completely comply with ISNCSCI. The committee supports communication, including questions, and expects constructive criticism as well.

Peer-review: This manuscript was prepared by the invitation of the Editorial Board and its scientific evaluation was carried out by the Editorial Board.

Conflict of Interest: No conflict of interest was declared by the author.

Financial Disclosure: The author declared that this study has received no financial support.

\section{References}

1. Kirshblum SC, Waring WP, Biering-Sorensen F, Burns SP, Johansen M, Schmidt-Read M, et al. Reference for the 2011 revision of the international standarts for neurological classification of spinal cord injury. J Spinal Cord Med 2011;34:547-54. [CrossRef] 
2. Michaelis LS. International inquiry on neurological terminology and prognosis in paraplegia and tetraplegia. Paraplegia 1969;7:1-5. [CrossRef]

3. Frankel HL, Hancock DO, Hyslop G, Melzak J, Michaelis LS, Ungar $\mathrm{GH}$, et al. The value of postural reduction in the initial management of closed injuries of the spine with paraplegia and tetraplegia. Paraplegia 1969;7:179-92. [CrossRef]

4. American Spinal Injury Association Standarts for neurological classification of spinal cord injured patients. Chicago, IL: ASIA; 1982.

5. Lucas JT, Ducker TB. Motor classification of spinal cord injuries with mobility, morbidity and recovery indices. Am Surg 1979;45: 151-8.

6. Kirshblum S, Waring W. Updates for the international standarts for neurological classification of spinal cord injury. Phys Med Rehabil Clin N Am 2014;25:505-17. [CrossRef]

7. Waters RL, Adkins RH, Yakura JS. Definition of complete spinal cord injury. Paraplegia 1991;29:573-81. [CrossRef]

8. American Spinal Injury Association/International Medical Society of Paraplegia (ASIA/IMSOP). International Standarts for Neurological and Functional Classification of Spinal Cord Injury Patirnts (revised). Chicago: American Spinal Injury Association; 1992.
9. American Spinal Injury Association/International Medical Society of Paraplegia. International Standarts for Neurological and Functional Classification of Spinal Cord Injury Patirnts. Chicago: American Spinal Injury Association; 1996.

10. American Spinal Injury Association/International Medical Society of Paraplegia. International Standarts for Neurological Classification of Spinal Cord Injury Patients. Chicago: American Spinal Injury Association; 2000.

11. Waring WP, Biering-Sorensen F, Burns SP, Donovan W, Graves D, Jha A, et al. 2009 review and revisions of the international standarts for the neurological classification of spinal cord injury. I Spinal Cord Med 2010;33:346-52.

12. Available from: http://lms3.learnshare.com/home.aspx. Accessed January 21, 2015.

13. Kirshblum SC, Burns SP, Biering-Sorensen F, Donovan W, Graves DE, Jha $A$, et al. International standarts for neurological classification of spinal cord injury. J Spinal Cord Med 2011;34:535-46. [CrossRef]

14. Gündüz B, Erhan B. Omurilik yaralanması nörolojik sınıflaması için uluslararası standartlar 2011 revizyonu: Değerlendirme formu Türkçe çevirisi. Turk J Phys Med Rehab 2012;58(Özel Sayı 1);42-5. 